\title{
PEMBELAJARAN KUAT GESER DAN KUAT TEKAN PADA TANAH LEMPUNG BERBASIS PRAKTIKUM
}

\author{
Suhairiani $^{1}$, Nahesson H. Panjaitan ${ }^{2}$, Hamidun Batubara ${ }^{3}$ \\ 1,2,3 Dosen Pengajar Jurusan Pendidikan Teknik Bangunan, Fakultas Teknik, UNIMED, Medan \\ Surel : suhairiani@unimed.ac.id \\ Diterima : 26 November 2017; Disetujui : 30 November 2017
}

\begin{abstract}
ABSTRAK
Kekuatan geser dan kuat tekan tanah adalah ilmu gaya perlawanan internal yang bekerja per satuan massa tanah untuk menahan keruntuhan sepanjang bidang yang runtuh dalam periode tanah dimana perlu diketahui kekuatan kekuatan geser dan kekuatan tekan pada tanah liat Namun, banyak siswa belum selesai mempelajarinya. Berbagai upaya dalam meningkatkan penguasaan materi, yaitu melalui metode praktis yang dirancang oleh mahasiswa untuk mengembangkan dan meningkatkan aktivitas belajar dalam memahami materi pelajaran dan keterampilan dasar untuk meningkatkan kemampuan eksperimental, terutama dengan menggunakan alat. Jenis penelitian yang digunakan adalah penelitian eksperimental dengan metode kuantitatif dengan desain penelitian kelompok pretest dan posttest. Instrumen yang digunakan adalah tes kemampuan kognitif, lembar observasi siswa dan dosen dan kuesioner. Hasil penelitian menunjukkan bahwa peningkatan kognitif mahasiswa sebesar $84.24 \%$ dan peningkatan psikomotor mahasiswa dengan kriteria sangat baik adalah $57,68 \%$ dan rata-rata respon mahasiswa sangat setuju dengan penerapan pembelajaran berbasis praktek. sekitar $88 \%$. Sehingga penerapan pembelajaran berbasis praktikum dapat digunakan untuk berbagai jenis kasus pertanahan yang ada terutama untuk pengujian yang berkaitan dengan kekuatan geser dan kuat tekan pada tanah liat
\end{abstract}

Kata Kunci : tanah liat, kekuatan tekan, kekuatan geser, praktikum

\begin{abstract}
The shear strength and compressive strength of the soil is the science of the internal resistance force acting per unit of soil mass to withstand collapse along the crumbling plane in the soil period for which it is necessary to know the strength of shear strength and compressive strength on the clay soil. However, many students have not finished in studying it. Various efforts in improving the mastery of the material, namely through practical methods designed by students to develop and improve learning activities in understanding the subject matter and basic skills to improve experimental skills, especially using tools. The type of research used is experimental research with quantitative method with pretest and posttest group research design. The instruments used are cognitive ability test, student observation sheet and lecturer and questionnaire. The results showed that students' cognitive improvement of $83.79 \%$ and psychomotor improvement of students with a very good criterion was $57.68 \%$ and the average response of students strongly agree with the application of practice-based learning. about $88 \%$. So that the application of practicum-based learning can be used for various types of land cases that exist especially for testing related to shear strength and compressive strength on clay.
\end{abstract}

Keywords: clay, compressive strength, practicum, shear strength

\section{Pendahuluan}

Pokok Bahasan Kuat geser dan kuat tekan merupakan bagian dari sekumpulan materi yang ada pada mata kuliah mekanika tanah dan praktikum mekanika tanah. Mata kuliah ini diberikan kepada mahasiswa D3 Teknik sipil dengan bobot 3 sks. Capaian kompetensi pada pokok bahasan ini adalah mahasiswa nantinya dapat menjelaskan kriteria keruntuhan mohrcoulomb pengukuran kekuatan geser tanah dengan uji geser langsung (Direct shear test), 


\section{Suhairiani - Nahesson H. Panjaitan - Hamidun Batubara}

triaxcial (triaxial test) serta pengukuran kekuatan geser tanah dengan uji tekan bebas (UCS). Pokok pembahasan ini diperoleh mahasiswa pada semester genap untuk teori dan semsetr ganjil untuk praktek

Hasil studi lapangan yang telah dilakukan di universitas negeri medan pada program studi D3 teknik sipil dapat diidentifikasi beberapa permasalahan dalam pembelajaran pada mata kuliah praktek mekanika tanah khususnya pada pokok bahasan kuat geser dan kuat tekan pada tanah, diantaranya adalah;

a. Pembelajaran masih beroreantasi hanya pada produk pengetahuan, kurang beroreantasi pada proses sains

b. Pembelajaran masih terfokus pada dosen sebagai sumber utama pengetahuan

c. Kurangnya keterampilan mahasiswa saat melaksanakan praktikum

d. Rendahnya hasil belajar mahasiswa

Metode praktikum pada umumnya dirancang secara khusus agar mahasiswa dapat mengembangkan aktivitas belajar, memperoleh fakta dari konsep yang dipelajarinya, mengembangkan ketrampilan dasar melakukan eksperimen khususnya ketrampilan menggunakan alat, kemampuan memecahkan masalah dengan pendekatan ilmiah, meningkatkan

pemahaman mengenai materi pelajaran, mengembangkan ketrampilan dasar melakukan observasi, mengkomunikasikan hasil observasi secara lisan maupun tulisan dan dapat memfasilitasi rekonstruksi konsep-konsep atau membangun konsep sehingga dosen berperan dalam penguatan dan mengkoreksi konsep yang keliru. Berdasarkan terminologinya, praktikum dapat diartikan sebagai suatu rangkaian kegiatan yang memungkinkan seseorang (siswa) menerapkan keterampilan atau mempraktikkan sesuatu (Subiantoro, 2009).

Menurut Joyce \& Weil, (2000). Pembelajaran berbasis praktikum memiliki sintaks yaitu :

a. Orientasi masalah guru menjelaskan area yang akan diselidiki serta langkah-langkah praktikum;

b. Perumusan masalah siswa merumuskan masalah, siswa mengidentifikasi langkah-langkah penyelidikan

c. Melakukan penyelidikan siswa mengidentifikasi masalah untuk diselidiki, siswa melakukan kegiatan penyelidikan, pengumpulan data interpretasi data, manipulasi variabel dalam penyelidikan, siswa mengindentifikasi kesulitan dalam proses penyelidikan;

d. Mengatasi kesulitan

guru menugaskan siswa untuk memikirkan berbagai cara dalam mengatasi kesulitan dalam proses penyelidikan, siswa merancang ulang percobaan, mengorganisasi data melalui berbagai cara, menginterpretasi data, mengkontruksi pengetahuan;

e. Merefleksikan hasil penyelidikan

mengaitkan hasil praktikum atau penyelidikannya dengan konsep atau teori

Rustaman, (2005) menyatakan Dalam proses belajar mengajar kegiatan laboratorium atau praktikum turut berperan dalam mencapai tiga tujuan pembelajaran antara lain adalah :

1) Keterampilan kognitif (melatih agar teori dapat dimengerti, agar teori dapat diterapkan pada keadaan nyata),

2) Ketrampilan afektif (belajar bekerja sama, belajar menghargai bidangnya, belajar merencanakan kegiatan secara mandiri)

3) Ketrampilan Psikomotorik (belajar memasang peralatan, belajar memakai perlatan dan instrumen tertentu)

\section{Metodologi}

Jenis penelitian yang digunakan dalam penelitian ini adalah penelitian eksperimen (experimen research) dengan metode kuantitatif. Desain penelitian "Pretest-Posttest Control Design" (Arikunto, 2010).

Berdasarkan skor pretes yang diperoleh maka ditentukan sampelnya, yaitu dengan melihat skor pretes mahasiswa yang sama atau tidak berbeda nyata, maka diperoleh sampel sebanyak 25 mahasiswa.

Selanjutnya menentukan kelas eksperimen dan kelas kontrol dengan cara random sampling. Instrumen yang digunakan meliputi:

1) Satuan Acara Pembelajaran (SAP),

2) Silabus,

3) Rencana Pelaksanaan Pembelajaran (RPP),

4) Penuntun praktikum,

5) Instrumen tes kemampuan kognitif,

6) Instrumen tes kemampuan psikomotorik,

7) Lembar observasi kemampuan dosen,

8) Angket tanggapan mahasiswa terhadap pembelajaran berbasis. 


\section{Pembelajaran Kuat Geser Dan Kuat Tekan Pada Tanah Lempung Berbasis Praktikum}

Peningkatan kemampuan kognitif dianalisis dengan skor gain yang dinormalisasi (Archambault, 2008) digunakan rumus:

$$
g=\frac{s_{\text {post test }}-S_{\text {pre test }}}{S_{\text {Maximum }}-S_{\text {pre test }}}
$$

Disini dijelaskan bahwa $\mathrm{g}$ adalah gain yang dinormalisasi (N-gain) dari kedua model, Smaks adalah skor maksimum (ideal) dari tes awal dan tes akhir, Spost adalah skor tes akhir, sedangkan Spre adalah skor tes awal. Tinggi rendahnya gain yang dinormalisasi ( $\mathrm{N}$-gain) dapat diklasifikasikan sebagai berikut: (1) jika g $\geq 0,7$, maka $\mathrm{N}$-gain yang dihasilkan termasuk kategori tinggi; (2) jika 0,7 > g $\geq 0,3$, maka Ngain yang dihasilkan termasuk kategori sedang, dan (3) jika g $<0,3$ maka $\mathrm{N}$-gain yang dihasilkan termasuk kategori rendah. Atau dapat disajikan seperti tabel dibawah ini.

Tabel 1. Kriteria N-gain Ternormalisasi

\begin{tabular}{cc}
\hline Perolehan N-gain & Kriteria \\
\hline $\mathrm{N}$-gain $>70$ & Tinggi \\
$30 \leq \mathrm{N}$-gain $\leq 70$ & Sedang \\
$\mathrm{N}$-gain $>30$ & Rendah \\
\hline
\end{tabular}

Analisa hasil observasi mahasiswa dan dosen dengan menggunakan rumus persentase sudjono (2001) sebagai beikut:

$$
P=\frac{F}{N} \times 100 \%
$$

Dengan $\mathrm{P}$ adalah nilai persen muculnya aspek kterampilan yang diamati, $\mathrm{F}$ adalah frekwensi yang muncul dan $\mathrm{N}$ adalah jumlah mahasiswa.

Menurut sugiono(2012) kriteria nilai observasi keteramilan mahasiswa dapat disajikan pada tabel sebagai berikut:

Tabel 2. Kriteria Nilai Observasi Mahasiswa

\begin{tabular}{cc}
\hline NIlai & Kriteria \\
\hline 4 & Sangat baik \\
3 & Baik \\
2 & Tidak Baik \\
1 & Sangat tidak Baik \\
\hline
\end{tabular}

Menurut Arikunto (2005)
observasi
ketrampitan
membimbing
mahasiswa dan mentai
pembelajaran
beikut:

Tabel 3. Kriteria Nilai Observasi Dosen

\begin{tabular}{cc}
\hline Persentase & Kriteria \\
\hline $80-100$ & Sangat Baik \\
$66-79$ & Baik \\
$56-65$ & Cukup \\
$40-55$ & Kurang \\
$30-39$ & Gagal \\
\hline
\end{tabular}

Tanggapan mahasiswa terhadap penerapan pembelajaran dianalisis dengan menggunakan rumus sebagai berikut :

$$
\% \text { tanggapan Mhs }=\frac{J L H \text { MHS yg menjawab }}{J L H M H S} \times 100 \%
$$

Dengan tanggpan mahasiswa yang menjawab Sangat Tidak Setuju (STS),Tdak Setuju (TS), agu - ragu (R), Setuju (S), dan Sangat Setuju (SS).

Menurut Koentjaraningrat (2000) hasil dan perhitungan tersebut di interperstasikan seperti pada tabel dibawah ini

Tabel 4. Interprestasi Tanggapan Mahasiswa terhadap pembelajaran berbasis praktikum

\begin{tabular}{cc}
\hline Persentase & Katagori \\
\hline $0 \%$ & Tidak ada \\
$1 \%-25 \%$ & Sebahagian kecil \\
$26 \%-49 \%$ & Hampir setengahnya \\
$50 \%$ & Setengahnya \\
$51 \%-75 \%$ & Sebahagian besar \\
$76 \%-99 \%$ & Pada umumnya \\
$100 \%$ & Seluruhnya \\
\hline
\end{tabular}

\section{Hasil dan Pembahasan}

\subsection{Kemampuan Kognitif}

Kemampuan kognitif adalah melihat kemampuan mahasiswa dalam mengerti teori dan dapat diterapkan pada keadaan nyata

Kemampuan awal mahasiswa penting untuk diketahui oleh dosen sebelum memulai proses pembelajaran, dengan demikian dosen dapat mengetahui apakah mahasiswa telah memiliki pengetahuan yang merupakan prasyarat untuk mengikuti pembelajaran dan sejauh mana mahasiswa telah mengetahui materi yang akan diberikan. Dengan mengetahui hal tersebut, dosen dengan mudah merancang pembelajaran dengan lebih baik, sebab apabila mahasiswa di beri materi yang telah diketahui maka mahasiswa akan merasa cepat bosan. Penentuan sampel penelitian juga dilakukan dosen dengan cara memberikan dan melihat skor kemampuan awal (pretes).

Kemampuan akhir mahasiswa yang diajarkan dengan menggunakan pembelajaran berbasis praktikum dapat diketahui ada 


\section{Suhairiani - Nahesson H. Panjaitan - Hamidun Batubara}

tidaknya peningkatan pemahaman konsep dari hasil penelitian, maka dilakukan suatu cara dengan menghitung selisih antara skor pretes dengan skor postes (Gain) kemudian dilakukan normalisasi gain (N-Gain) untuk mengetahui skor asli mahasiswa serta untuk mengetahui ada tidaknya peningkatan kemampuan kognitif atau pemahaman konsep seperti yang ditunjukkan pada Gambar 1.



Gambar 1. Penigkatan Kemampuan Kognitif

Berdasarkan Gambar 1 diatas, dapat dilihat bahwa kemampuan kognitif mahasiswa sebelum dilakukannya eksperiment lebih rendah daripada telah dilakukannya eksperiment. Hal ini diuji dari kemampuan mahasiswa yang diajarkan pada penerapan pembelajaran berbasis praktikum daripada pembelajaran dengan metode ceramah. Mahasiswa lebih bisa mudah memahami dan mengerti tentang materi yang disampaikan, dan mahasiswa dapat bisa mengembangkan analisis hasil data eksperiment yang telah dilakukan. Dan nilai gain yang dihasilkan dengan nilai $84.24 \%$ termasuk katagori tinggi karena nilai Gain lebih besar dar 70\%.

\subsection{Kemampuan Psikomotorik}

Kemampuan pskomotorik adalah melihat kemampuan mahasiswa dalam belajar memakai peralatan dan instrument tertentu.

Perbandingan nilai persentase dari kemampuan mahasiswa dalam penggunaan alat dan melakuka percobaan dapat dilihat pada Gambar 2 diagram batang dibawah ini.

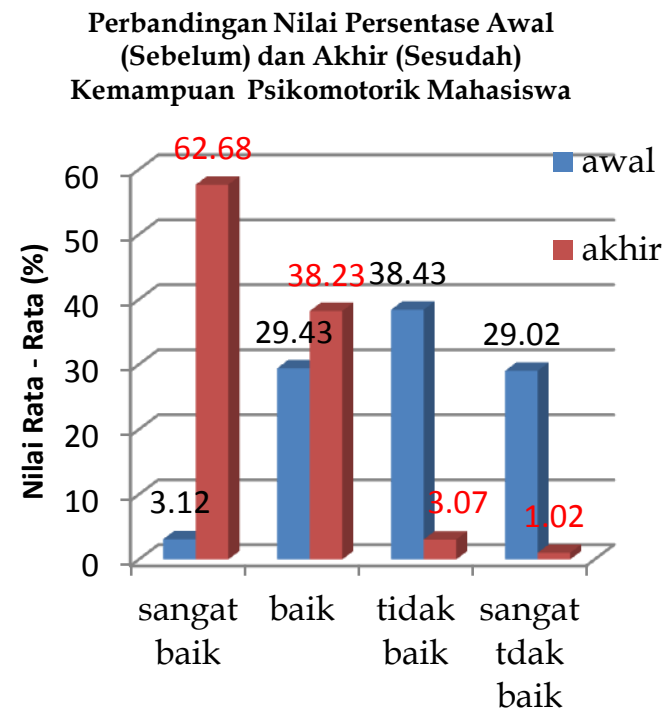

kemampuan Psikomotorik mahasiswa

Gambar 2. Peningkatan Kemampuan Psikomotorik

Berdasarkan Gambar 2 di atas dapat diketahui persentase peningkatan kemampuan psikomotorik mahasiswa pada pengunnaan alat dan melakukan jenis percobaan dari beberapa jenis tanah lempung. Dari data tersebut terlihat jelas perbandingan peningkatan kemampuan psikomotorik mahasiswa. Perbandingan antara kedua kelas tersebut merupakan hasil ratarata dan persentase dari beberapa aspek kemampuan psikomotorik yang diamati.

Hal ini menunjukkan bahwa penerapan pembelajaran berbasis praktikum lebih efektif untuk meningkatkan kemampuan psikomotorik mahasiswa pada pokok bahasan kuat geser dan kuat tekan

\subsection{Kemampuan Dosen Membimbing dan Melaksanakan Kegiatan Praktikun}

Dalam pelaksanaan pembelajaran berbasis praktikum ini, peran dosen adalah sebagai fasilitator, pembimbing yaitu memberikan petunjuk dan arahan serta mengatur jalannya pembelajaran. Sehingga peningkatan kemampuan kognitif dan psikomotorik yang diharapkan dalam suatu pelaksanaan pembelajaran berbasis praktikum tercapai. Bimbngan dan pelaksanaan yang baik dalam kegiatan praktikum yang dilaksanakan oleh dosen sangat berpengaruh terhadap peningkatan kemampuan kognitif dan psikomotorik mahasiswa. 


\subsection{Tanggapan Mahasiswa Terhadap Pembelajaran Berbasis Praktikum}

Angket tanggapan mahasiswa terhadap pembelajaran berbasis praktikum dapat dilihat pada Tabel 5 dibawah ini.

Tabel 5 :Tanggapan Mahasiswa terhadap Pembelajaran Berbasis praktikum

\begin{tabular}{|c|c|c|c|c|c|}
\hline \multirow{2}{*}{ Katagori } & \multicolumn{5}{|c|}{ Tanggapan (\%) } \\
\hline & STS & TS & $\mathbf{R}$ & $\mathbf{S}$ & SS \\
\hline $\begin{array}{l}\text { Kepedulian } \\
\text { mahasiswa } \\
\text { terhadap inovasi } \\
\text { pembelajaran }\end{array}$ & 0 & 0 & 8 & 12 & 80 \\
\hline $\begin{array}{l}\text { Ketertarikan } \\
\text { Mahasiswa } \\
\text { terhadap } \\
\text { pembelajaran } \\
\text { berbasis } \\
\text { praktikum }\end{array}$ & 0 & 0 & 4 & 4 & 92 \\
\hline $\begin{array}{l}\text { Tanggpan } \\
\text { mahasiswa pada } \\
\text { saat pembelajaran } \\
\text { berbasis } \\
\text { praktikum }\end{array}$ & 0 & 0 & 0 & 12 & 88 \\
\hline $\begin{array}{l}\text { Penilaian } \\
\text { terhadap } \\
\text { pembelajaran } \\
\text { berbasis } \\
\text { praktikum } \\
\end{array}$ & 0 & 0 & 4 & 4 & 92 \\
\hline
\end{tabular}

Berdasarkan Tabel 5 diatas dapat dilihat bahwa pembelajaran berbasis praktikum sangat membantu mahasiswa dalam meningkatkan minat dan ketertarikan mahasiswa dalam pembelajaran berbasis praktikum, karena dengan dilakukannya pembelajaran berbasis praktikum, mahasiswa dapat mengexplore kemampuan dan rasa ingin tau.

Hal ini ditunjukkan dari tanggapan mereka terhadap:

> sikap kepedulian mahasiswa terhadap inovasi pembelajaran,

$>$ ketertarikan mahasiswa terhadap pembelajaran berbasis praktikum,

$>$ tanggapan mahasiswa pada saat proses pembelajaran berbasis praktikum berlangsung

$>$ penilaian terhadap pembelajaran berbasis praktikum.

\section{Simpulan}

Berdasarkan hasil penelitian dan pembahasan, maka dapat disimpulkan sebagai berikut :

1) penerapan pembelajaran berbasis praktikum dapat meningkatkan kognitif mahasiswa pada pokok bahasan kuat geser dan kuat tekan dengan kriteria tinggi atau N-Gain 84.24\%

2) Penerapan pembelajaran berbasis praktikum dapat meningkatkan kemampuan psikomotorik mahasiswa pada pokok bahasan kuat geser dan kuat tekan dengan kriteria sangat baik yaitu $62.68 \%$.

3) Kemampuan dosen dalam membimbing dan melaksanakan kegiatan praktikum sangat baik

4) yaitu 100\%, sehingga meningkatkan kemampuan kognitif dan psikomotorik mahasiswa.

5) Penerapan pembelajaran berbasis praktikum pada pokok bahasan kuat geser dan kuat tekan mendapat rata - rata tanggapan sekitar $88 \%$ mahasiswa menjawab sangat setuju dengan penerapan pembelajaran berbasis praktikum.

\section{Daftar Pustaka}

Utomo dan Ruijter, Kees. (1989). Peningkatan dan Pengembangan Pendidikan. Jakarta: PT Gramedia.

Depdiknas. (2006). Panduan Pengembangan Bahan Ajar. Jakarta: Ditjen Mandikdasmen.

Subiantoro, A.W. 2009. Pentingnya Praktikum Dalam Pembelajaran IPA. Tersedia di:http://vahonov.files.wordpress.c om/2009/07/pentingnyapraktikum-dalampembelajaran

Rustamam, N.Y. 2005. Strategi Belajar Mengajar. JICA, Bandung.

Joyce, B., dan Weil, M. 2000. Models of Teaching (Model-Model Pembelajaran). Pustaka Pelajar, Yogyakarta.

Archambault, J. 2008. The Effects of Developing Kinematics Concepts Graphically Prior to Introducing Algebraic Problem Solving Techniques. Action Research required for the Master of Natural Science degree with concentration in physics; Arizona State University.

Widodo, A., dan Ramdhaningsih, V. 2006. Analisis kegiatan praktikum biologi dengan menggunakan video. Metalogika. 9(2):146-158. 